\title{
A Dose Finding Study of a Super Long-Acting Luteinizing Hormone-Releasing Hormone Analog (Leuprolide Acetate Depot, TAP-144-SR) in the Treatment of Central Precocious Puberty
}

\author{
Toshiaki TANAKA, Itsuro HIBI, Kiyohiko KATO*, \\ Siro SAITO**, NaOtaka SHIMIZU***, Seizo SUWA****, \\ Hironori NAKAJIMA***** AND The TAP-144-SR CPP \\ STUdY GROUP ${ }^{\dagger}$ \\ Division of Endocrinology \& Metabolism, National Children's \\ Hospital, and Endocrine Research Laboratory, National Children's \\ Medical Research Center, Tokyo 154, *Department of Pediatrics, \\ Yamanashi Medical College, Yamanashi 409-38, **1st Department of Internal \\ Medicine, Tokushima University, Tokushima 770, ***3rd Department of Internal \\ Medicine, Teikyo University, Tokyo 173, ****Division of Endocrinology $\mathcal{F}^{\circ}$ \\ Metabolism, Kanagawa Children's Medical Center, Yokohama 232, and *****Department \\ of Pediatrics, Chiba University, Chiba 280, Japan
}

\begin{abstract}
The effect of leuprolide acetate (D-Leu ${ }^{6}-\left[\right.$ des-Gly $\left.{ }^{10}-\mathrm{NH}_{2}\right]-\mathrm{LH}-\mathrm{RH}$ ethylamide acetate) for depot suspension (TAP-144-SR), a synthetic analog of luteinizing hormone-releasing hormone, was examined in three doses in 36 patients ( 34 girls, 2 boys) with central precocious puberty. TAP-144-SR was injected subcutaneously every four weeks for twelve weeks, and clinical symptoms and plasma and urinary levels of various hormones were followed every four weeks. Eleven girls given $10 \mu \mathrm{g} / \mathrm{kg}$ showed a significant decrease in peak plasma LH and FSH responses to LH-RH test, but basal plasma LH and FSH did not change significantly. In 13 patients ( 11 girls and 2 boys) given $30 \mu \mathrm{g} / \mathrm{kg}$ and 12 girls given 90 $\mu \mathrm{g} / \mathrm{kg}$, both basal and peak LH and FSH were significantly suppressed. Urinary excretion of LH decreased significantly in all groups except in the $10 \mu \mathrm{g} / \mathrm{kg}$ group. Urinary excretion of FSH did not change significantly in the 10 and $30 \mu \mathrm{g} / \mathrm{kg}$ groups, but it decreased significantly in the $90 \mu \mathrm{g} / \mathrm{kg}$ group. In girls, plasma and urinary estradiol also fell greatly, but the difference was insignificant except in the $90 \mu \mathrm{g} / \mathrm{kg}$ group. Regression of sexual characteristics was observed in almost half of the patients at the 12 th week of the treatment. Side effects were minimal. A dose of more than $30 \mu \mathrm{g} / \mathrm{kg}$ of TAP-144-SR is effective in suppressing gonadotropins and causing improvement of clinical symptoms, and appears to be useful in treating children with central precocious puberty.
\end{abstract}

\begin{abstract}
ADMINISTRATION of long-acting analogs of luteinizing hormone-releasing hormone (LH-RH) has been shown to inhibit the release of luteinizing hormone (LH) and follicle-stimulating hormone

Received: March 6, 1991

Accepted: June 21, 1991

Correspondence to: Dr. Toshiaki TANAKA, Endocrine Research Laboratory, National Children's Medical Research Center, 3-35-31 Taishido, Setagaya-ku, Tokyo 154, Japan.
\end{abstract}

(FSH) [1]. Several LH-RH analogs have been used successfully to treat central precocious puberty. LH-RH analog (LH-RHa) has been administered in the past as a daily sc injection [1-7] or a thrice daily intranasal application $[7,8]$. Recently, it has been reported that a single in depot injection is effective in suppressing gonadotropins [9-11]. However, a dose finding study has not yet been done. 
We studied the effect of the injection of leuprolide acetate for depot suspension (TAP-144-SR) in three doses on gonadotropin secretion and plasma sex steroid hormone in children with central precocious puberty during the twelve-week treatment period.

\section{Materials and Methods}

\section{$L H-R H a$}

Leuprolide acetate is a synthetic nonapeptide analog of LH-RH (D-Leu ${ }^{6}$-des-Gly $\left.{ }^{10}-\mathrm{NH}_{2}\right]-\mathrm{LH}-$ RH ethylamide acetate). The long acting release form is prepared as microcapsules containing leuprolide acetate (Leuprolide acetate depot; TAP-144-SR). TAP-144-SR was supplied by Takeda Chemical Industries Ltd., in vials containing $1.88 \mathrm{mg}$ of leuprolide acetate.

\section{Patients}

Thirty-four girls, $0.75-10.83 \mathrm{yr}$ old, and two boys, $9.42 \mathrm{yr}$ and $9.58 \mathrm{yr}$ of age, were studied after informed consent was obtained from their parents. All patients had secondary sexual characteristics consistent with precocious puberty at diagnosis, i.e. advanced bone age, pubertal LH and FSH responses to the LH-RH stimulation test, and pubertal sex steroid levels. Twenty-seven patients were of the idiopathic central precocious puberty type and in nine patients causes were organic such as hypothalamic hamartoma, hydrocephalus, optic glioma, ependymoma and astrocytoma. Breech delivery had affected four patients $(11 \%)$ and asphyxia had been observed at birth in five patients (14\%). Seven patients (19\%) showed signs of mental retardation. Table 1 shows the clinical features of the three groups given different doses. Two boys were included in group II $(30 \mu \mathrm{g} / \mathrm{kg})$.

\footnotetext{
The TAP-144-SR CPP Study Group consists of the following personnel: Yukitaka Miyachi, Toho University; Kazue Takano, Tokyo Women's Medical College; Naoki Kageyama, Kishiwada City Hospital; Kazue Fujiwara, Bokuto Hospital; Kenji Fujieda, Hokkaido University; Yutaka Igarashi, Tohoku University; Nobutake Matsuo, Keio Gijuku University; Takashi Koshimizu, Kitazato University; Yoshio Igarashi, Hamamatsu Medical College; Masamichi Ogawa, Nagoya University; Shintaro Okada, Osaka University; Yoshikazu Nishi, Hiroshima Red-Cross Hospital; Norihisa Shirakawa, Tokushima University; Hitoshi Kono, Fukuoka City Children's Hospital; Hiroaki Takahashi, Kanazawa Medical College; Yoshiro Tsuji, Nagasaki Univesity; Naoya Kohda, Saitama Children's Medical Center; Motoko Ojima, Fukushima Medical College.
}

No previous treatment had been given to 29 patients. Four patients had been previously treated with daily administration of Buserelin (D-Ser ${ }^{6}$-[des-Gly $\left.{ }^{10}-\mathrm{NH}_{2}\right]-\mathrm{LH}-\mathrm{RH}$ ethylamide) which had been discontinued at least one month before the start of TAP-144-SR treatment, and three patients had been previously treated with cyproterone acetate, which had been discontinued at least six months before the start of treatment.

\section{Study procedures}

Patients were randomly divided into three groups and given one of three doses of TAP-144SR, $10 \mu \mathrm{g} / \mathrm{kg}$ (group I), $30 \mu \mathrm{g} / \mathrm{kg}$ (group II) or 90 $\mu \mathrm{g} / \mathrm{kg}$ (group III), as a sc injection every four weeks. The patients were followed up during the twelve-week treatment period.

Documentation of age at onset of puberty, height, weight, Tanner pubertal staging, testicular size and bone age by the Tanner-Whitehouse II method was obtained before treatment. A LH-RH test was performed before and every four weeks after the start of treatment. Plasma testosterone in males, plasma estradiol in females, plasma prolactin, plasma DHEA-S, plasma Sm-C, urinary LH and FSH, and urinary 17-KS, 17-OHCS and estradiol in 24-h urine were determined every four weeks. Tanner staging and testicular size were examined every four weeks. Adverse effects were monitored during the treatment period.

Plasma and urinary gonadotropins were determined by immunoradiometric assay (IRMA) [12] with a Spac kit (Daiichi Radio-Isotope). The quantitative detection limit was $0.2 \mathrm{mIU} / \mathrm{m} l$ in plasma LH and FSH. Plasma Sm-C, plasma testosterone and plasma estradiol were measured by radioimmunoassay (RIA). The quantitative detection limit was $6-10 \mathrm{pg} / \mathrm{ml}$ in estradiol and $20-50$ $\mathrm{ng} / \mathrm{d} l$ in testosterone.

\section{Statistical analysis}

The data are presented as the mean \pm standard deviation (SD). The results were analyzed by Student's two-tailed $t$-test and one-way analysis of variance (ANOVA). $\mathrm{P}<0.05$ was considered statistically significant.

\section{Results}

Figs. 1 and 2 show the change in the basal 
gonadotropins during the treatment period. Basal LH was significantly increased compared to the prepubertal normal range (shown by the shadow in the figures) before treatment, but basal FSH was within the normal range. Basal LII and FSH were significantly suppressed by TAP-144-SR administration in groups II and III, but not suppressed in group I.

The change in peak gonadotropins in the LH-RH test is shown in Figs. 3 and 4. Peak LH was significantly higher than the prepubertal normal range (shown by the shadow in the figures) and decreased significantly to the normal prepubertal range in all doses (Fig. 3). At eight weeks, peak $\mathrm{LH}$ in group I was significantly higher than in groups II and III. Peak FSH was not significantly higher than that of normal prepubertal children, but was decreased significantly by TAP-144-SR treatment in a dose-dependent manner (Fig. 4).

Urinary excretion of LH decreased significantly in all groups except group I (Fig. 5). Urinary excretion of FSH did not change significantly in group I, but it decreased significantly in group III (Fig. 6).

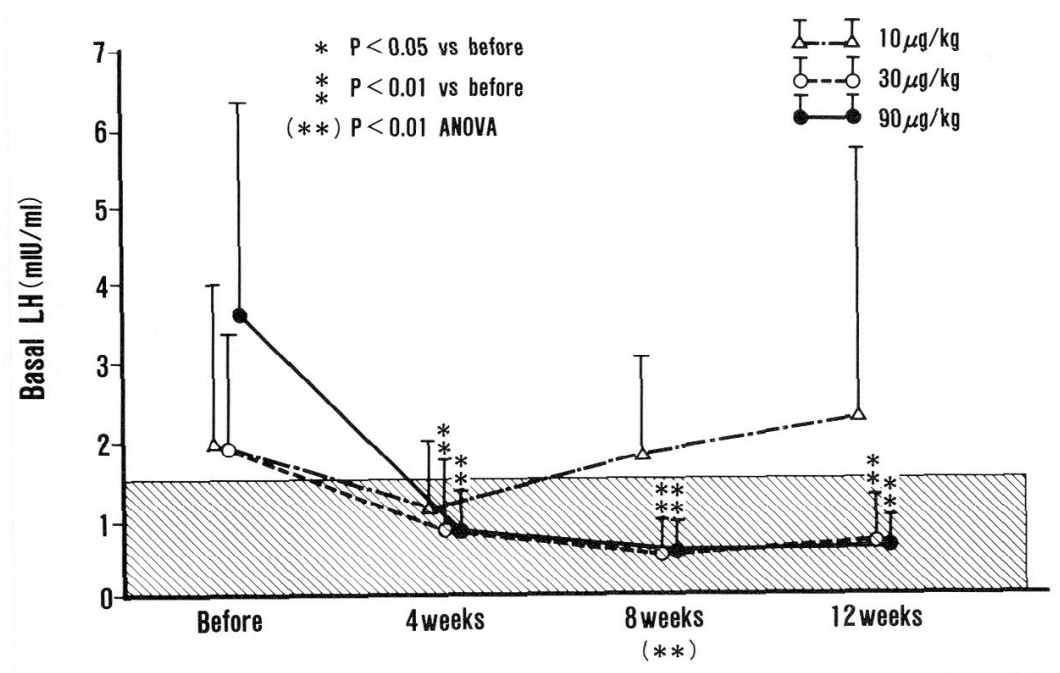

Fig. 1. Mean $( \pm \mathrm{SD})$ basal plasma LH levels before and during TAP-144-SR treatment measured by IRMA in three groups with central precocious puberty. Shaded area shows normal prepubertal range.

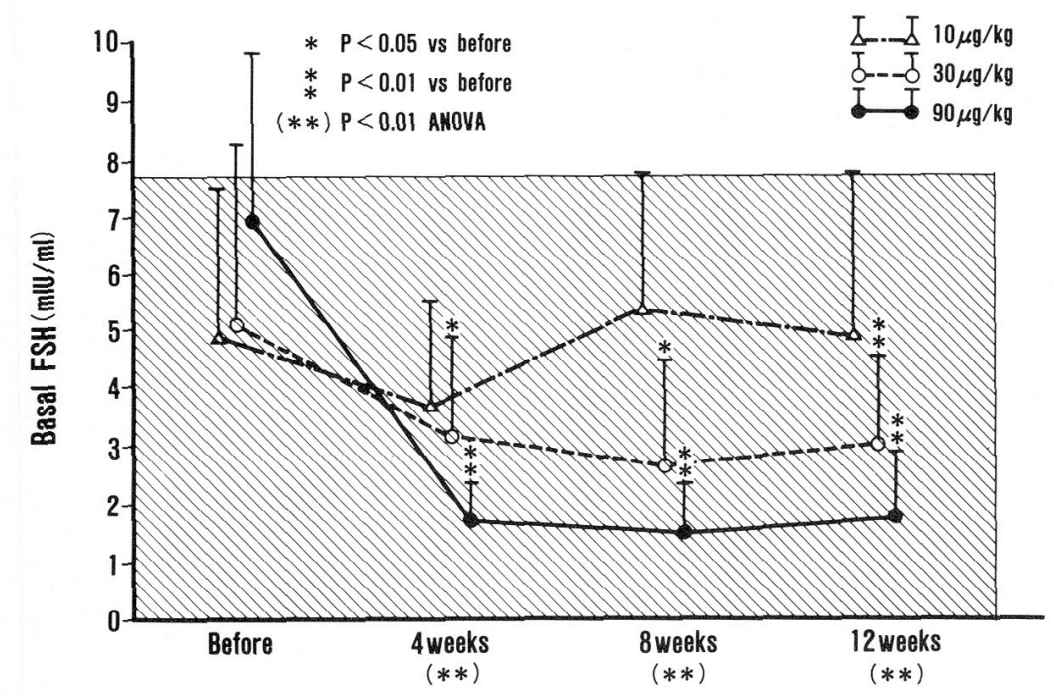

Fig. 2. Mean ( \pm SD) basal plasma FSH levels before and during TAP-144-SR treatment measured by IRMA in three groups with central precocious puberty. Shaded area shows normal prepubertal range. 


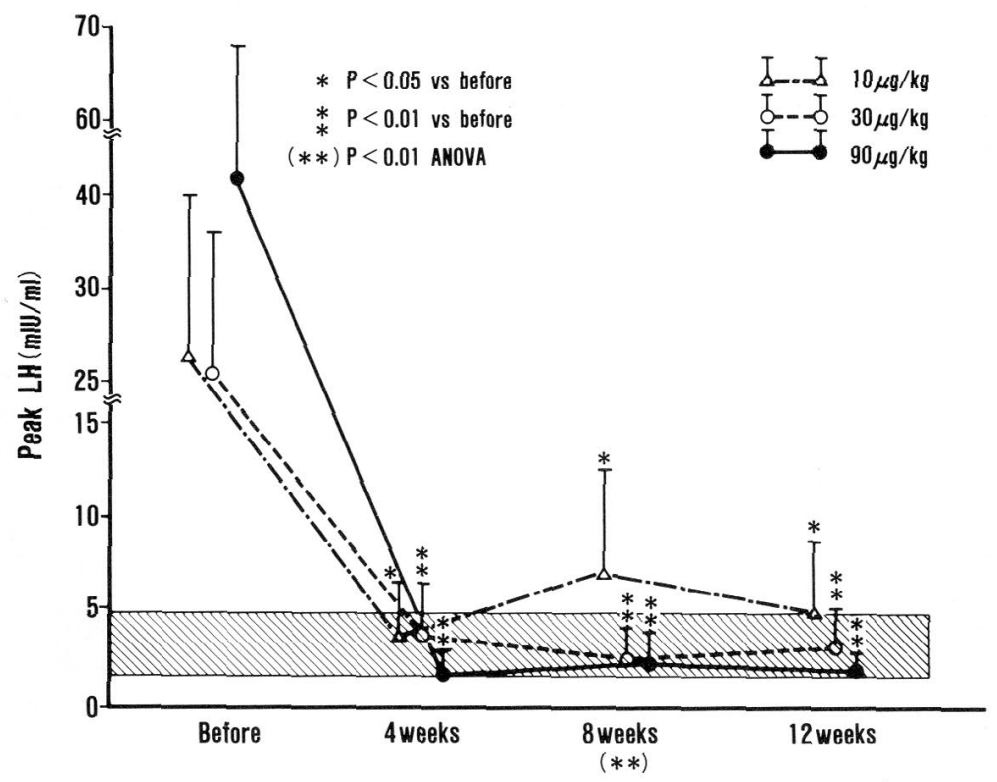

Fig. 3. Mean $( \pm \mathrm{SD})$ peak plasma $\mathrm{LH}$ response to LH-RH test before and during TAP-144-SR treatment measured by IRMA in three groups with central precocious puberty. Shaded area shows mean \pm SD of peak LH response in normal girls.

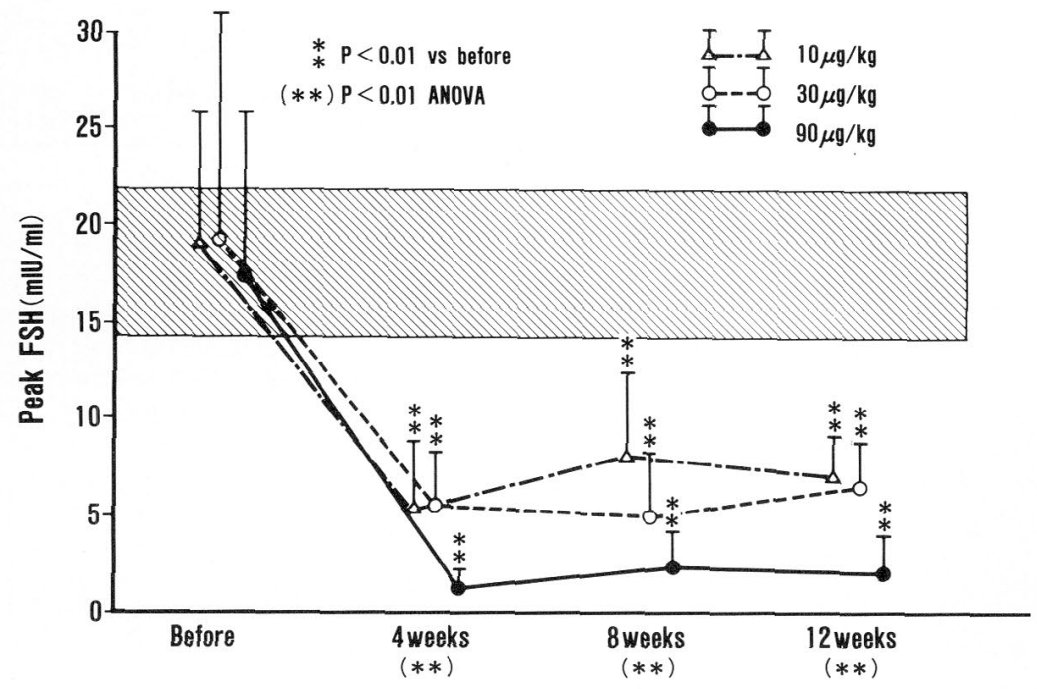

Fig. 4. Mean ( \pm SD) peak plasma FSH response to LH-RH test before and during TAP-144-SR treatment measured by IRMA in three groups with central precocious puberty. Shaded area shows mean \pm SD of peak FSH response in normal girls.

Plasma and urinary estradiol decreased in all groups, but significance was recognized only in group III (Fig. 7). Testosterone in boys decreased from $160 \mathrm{ng} / \mathrm{d} l$ to $70 \mathrm{ng} / \mathrm{d} l$ in one and remained at $50 \mathrm{ng} / \mathrm{d} l$ in the other.

Plasma Sm-C did not change significantly in groups I and II, but it decreased significantly in group III (Fig. 8). There was no significant change in urinary $17-\mathrm{KS}$ and 17-OHCS, plasma prolactin and plasma DHEA-S during the treatment period.

At 12 weeks of treatment, advancement of Tanner staging in pubic hair was noticed in one patient in group I, while regression of pubic hair was noticed in another patient in group I and two 


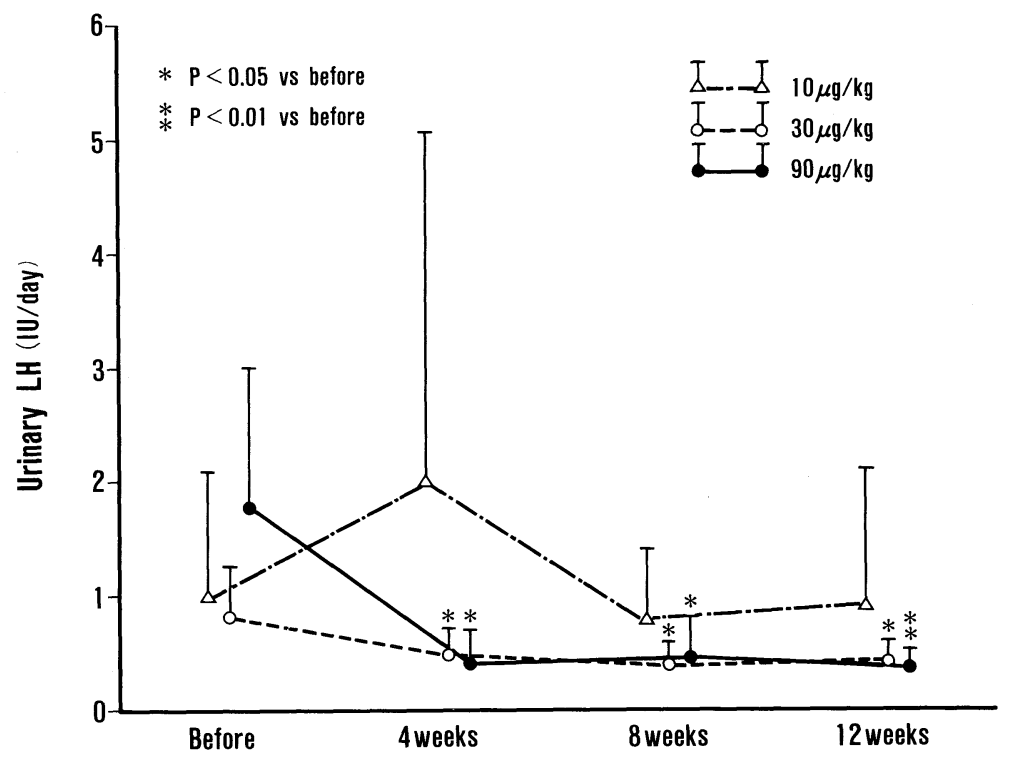

Fig. 5. Mean $( \pm S D)$ urinary LH levels before and during TAP-144-SR treatment measured by IRMA in three groups with central precocious puberty.

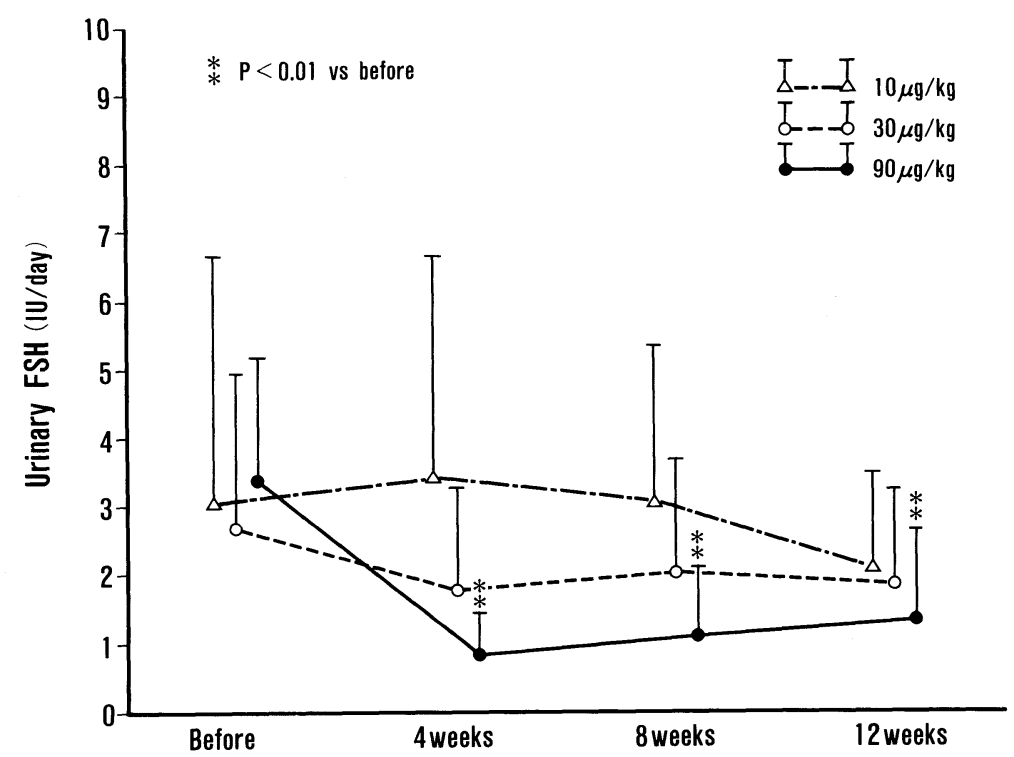

Fig. 6. Mean $( \pm \mathrm{SD})$ urinary FSH levels before and during TAP-144-SR treatment measured by IRMA in three groups with central precocious puberty.

patients in group III. Regression of breast development was recognized in six patients in group I, one patient in group II and five patients in group III. Of eight girls who showed genital bleeding before treatment, only one patient in group I still had that symptom after 12 weeks of treatment. For four weeks after the first injection, one girl in group II and four girls in group III had transient genital bleeding for a few days. Testicular volume decreased from $15 \mathrm{ml}$ to $12 \mathrm{ml}$ in one boy and from $10 \mathrm{~m} l$ to $8 \mathrm{~m} l$ in the other. 


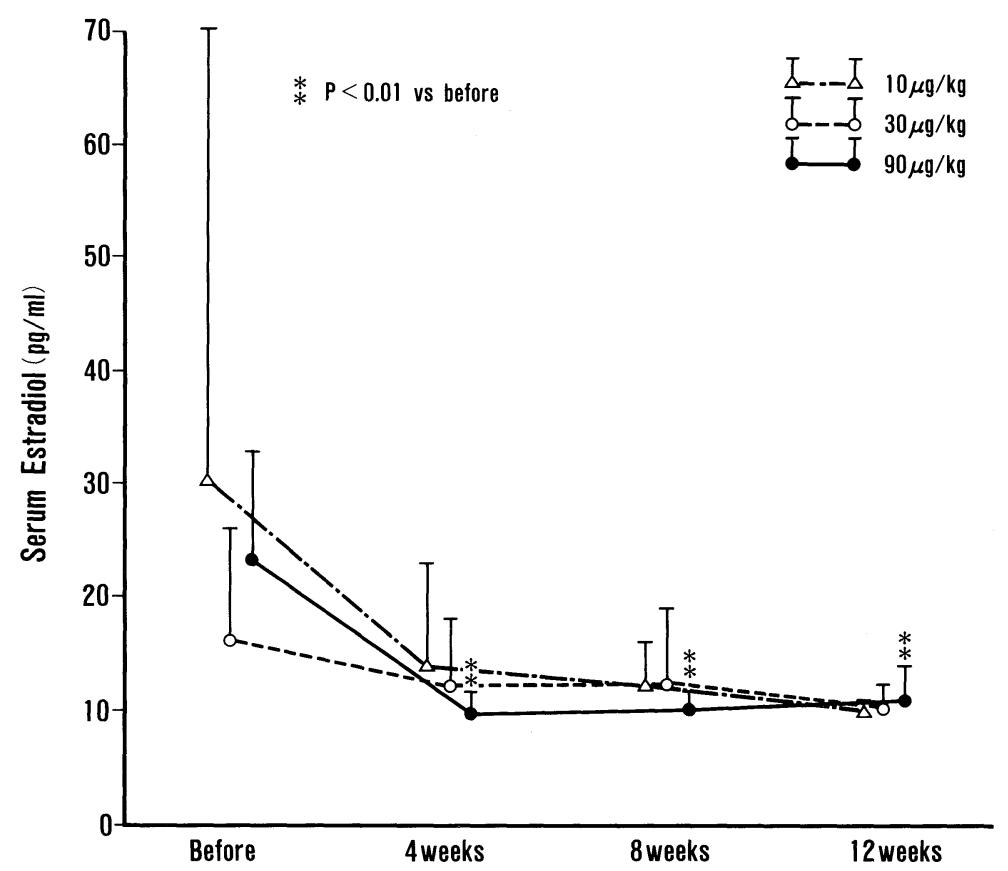

Fig. 7. Mean $( \pm \mathrm{SD})$ plasma estradiol levels before and during TAP-144-SR treatment in three groups of girls with central precocious puberty.

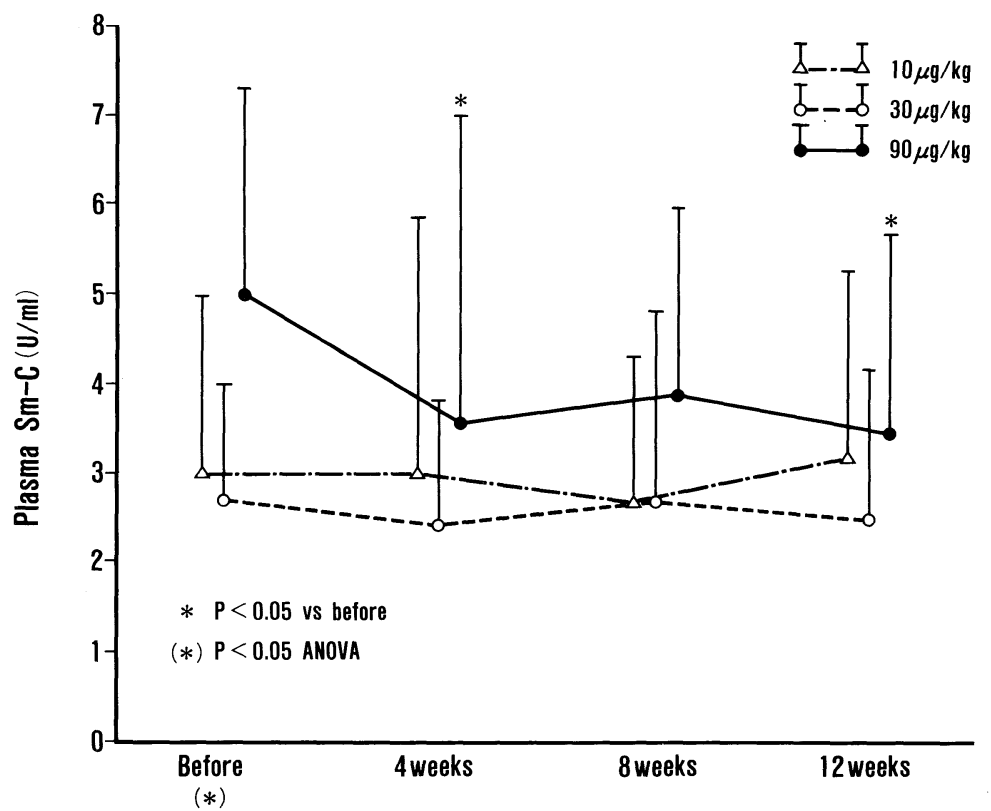

Fig. 8. Mean ( \pm SD) plasma Sm-C levels before and during TAP-144-SR treatment in three groups with central precocious puberty.

\section{Discussion}

Treatment of precocious puberty is not fully established. It is accepted that cypreterone acetate is effective in reducing the clinical manifestations of precocious puberty, but the effects on gonadotropins and sex steroids are not sufficient. The effect of LH-RHa on the suppression of gonadotropins is remarkable, but the method of administration is not practical and acceptable for patients. 
Table 1. Clinical characteristics in three groups with central precocious puberty

\begin{tabular}{lrcc}
\hline & Group I & Group II & Group III \\
\hline Dose $(\mu \mathrm{g} / \mathrm{kg})$ & 10 & 30 & 90 \\
Sex male & 0 & 2 & 0 \\
$\quad$ female & 11 & 11 & 12 \\
Chronological age (years) & $7.8 \pm 2.2$ & $6.1 \pm 2.5$ & $7.3 \pm 3.0$ \\
Bone age (years) & $9.2 \pm 3.3$ & $7.3 \pm 3.3$ & $9.0 \pm 3.3$ \\
Height (cm) & $127.5 \pm 16.0$ & $121.1 \pm 17.3$ & $124.3 \pm 17.0$ \\
Height velocity (cm/year) & $7.6 \pm 2.4$ & $12.5 \pm 8.5$ & $10.0 \pm 3.3$ \\
\hline
\end{tabular}

Since TAP-144-SR was a super-long acting LHRHa prepared for practical treatment, we conducted the dose finding study.

Sensitive gonadotropin measurement by IRMA revealed that prepubertal gonadotropin levels were lower than those measured by RIA. It is well known that pulsatile secretion and increase in $\mathrm{LH}$ is important in developing puberty $[13,14]$. The 24-h LH profile as well as the LH-RH test is useful in evaluating pubertal stages $[12,15]$. In our study, the basal LH level had a close correlation $(\mathrm{r}=0.822, \mathrm{p}<0.0001, \mathrm{n}=129)$ with peak LH in the LH-RH test. Therefore, basal LH is also useful in evaluating pubertal stages. Since urinary measurement of gonadotropins by IRMA showed parallel change with basal plasma gonadotropins, urinary gonadotropin is also useful as another indicator.

In a previous report [11], a dose of $300 \mu \mathrm{g} / \mathrm{kg}$ leuprolide acetete for depot suspension was injected intramuscularly. However, the rationale of such a high dose is unclear. Therefore, we conducted the study to find out the least effective dose in treating precocious puberty. This dose finding study demonstrated that three doses of TAP-144SR were effective in suppressing plasma peak gonadotropins in the LH-RH test, but $10 \mu \mathrm{g} / \mathrm{kg}$ was not enough to suppress basal plasma gonadotropins. Although sex hormones decreased at all doses, it was difficult to make a precise evaluation because the RIAs for sex steroids did not detect low levels of these steroids. Even in the short period of this study, TAP-144-SR treatment induced a remarkable improvement in pubertal signs, such as breast development, testicular size, and vaginal bleeding, in almost half of the patients. Progression of Tanner staging in pubic hair and persistent genital bleeding was recognized in group I. From the endocrinological and clinical point of view, $10 \mu \mathrm{g} / \mathrm{kg}$ was not a sufficient dose to treat central precocious puberty. Therefore, we recommend that newly diagnosed patients should be treated with a dose of $30 \mu \mathrm{g} / \mathrm{kg}$. However, a few patients in group II continued to have high basal LH levels. This might indicate that there are varieties of this disease with different virulencies. A dose of $90 \mu \mathrm{g} / \mathrm{kg}$ may be necessary in some cases and seems to be enough in treating central precocious puberty. In all groups, peak FSH response to the LH-RH test decreased below the normal prepubertal range during treatment. The mechanism and significance of this phenomenon are unknown.

It is well known that cyproterone acetate treatment suppresses the adrenal gland function [16, 17]. Measurement of urinary 17-KS, 17-OHCS and plasma DHEA-S demonstrated that TAP-144SR had no influence on adrenal function. Plasma prolactin and plasma Sm-C did not change significantly during the 12-week treatment period. Harris et al. [5] reported a decrease in Sm-C levels after suppression of gonadal sex steroid, but the change only became significant after six months of LH-RHa therapy. To observe the normalization of plasma Sm-C, longer follow-up of patients may be needed.

No side effects of treatment with TAP-144-SR were observed except for transient genital bleeding after the first injection in four girls. This bleeding was due to the LH-RH-like stimulatory effect of TAP-144-SR.

In conclusion, on the basis of hormonal changes and clinical symptoms, a dose of more than 30 $\mu \mathrm{g} / \mathrm{kg}$ of TAP-144-SR is recommended in treating central precocious puberty. A single subcutaneous injection every four weeks is practical and more acceptable for patients than daily injections. It is reported that cyproterone acetate treatment did not obtain sufficient adult heights [18]. The final 
effect of this treatment remains to be established.

\section{Acknowledgements}

The authors are grateful to Takeda Chemical Ind. Ltd. for contributing TAP-144-SR.

\section{References}

1. Crowley WF, Comite F, Vale W, Rivier J, Loriaux DL, Culter GB (1981) Therapeutic use of pituitary desensitization with a long acting LHRH agonist: a potential new treatment for idiopathic precocious puberty. J Clin Endocrinol Metab 52: 370-372.

2. Comite F, Pescovitz OH, Rieth KG, Dwyer AJ, Hench K, McNemar A, Loriaux DL, Culter GB (1984) Luteinizing hormone-releasing hormone analog treatment of boys with hypothalamic hamartoma and true precocious puberty. J Clin Endocrinol Metab 59: 888-892.

3. Styne DS, Harris DA, Egli CA, Conte FA, Kaplan SL, Rivier J, Vale W, Grumbach MM (1985) Treatment of true precocious puberty with a potent luteinizing hormone-releasing factor agonist: effect on growth, sexual maturation, pelvic sonography, and the hypothalamic-pituitarygonadal axis. J Clin Endocrinol Metab 61: 142-15l.

4. Prescovitz OH, Comite F, Hench K, Barnes K, McNemar A, Foster C, Kenigsberg D, Loriaux DL, Cutler GB (1986) The NIH experience with precocious puberty: diagnostic subgroups and response to short-term luteinizing hormone releasing hormone analogue therapy. Pediatr 108: $47-54$.

5. Harris DA, Van Vliet G, Egli CA, Grumbach MM, Kaplan SL, Syne DM, Vainsel M (1985) Somatomedin- $\mathrm{C}$ in normal puberty and in true precocious puberty before and after treatment with a potent luteinizing hormone-releasing hormone agonist. J Clin Endocirnol Metab 61: 152-159.

6. Lee PA, Page JD, The Leuprolide Study Group (1989) Effects of leuprolide in the treatment of central precocious puberty. J Pediatr 114 :321-324.

7. Luder AS, Holland FJ, Costigan DC, Jenner MR, Wielgosz G, Fazekas ATA (1984) Intranasal and subcutaneous treatment of central precocious puberty in both sexes with a long-acting analog of luteinizing hormone-releasing hormone. J Clin Endocrinol Metab 58: 966-972.

8. Stanhope R, Pringle PJ, Brook CGD (1988) Growth, growth hormone and sex steroid secretion in girls with central precocious puberty treated with a gonadotropin releasing hormone $(\mathrm{GnRH})$ analogue. Acta Paediatr Scand 77: 525-530.

9. Roger M, Chaussain JL, Berlier P, Bost M, Canlorbe P, Colle M, Francois R, Garandeau P, Lahlou N, Morel Y, Shally AV (1986) Long term treatment of male and female precocious puberty by periodic administration of a long-acting preparation of D-Trp ${ }^{6}$-luteinizing hormone-releasing hormone microcapsules. J Clin Endocrinol Metab 62: 670-677.

10. Lahlou N, Roger M, Chaussain J-L, Feinstein M-C, Sultan C, Toublanc JE, Schally AV, Sholler R (1987) Gonadotropin and $\alpha$-subunit secretion during long term pituitary suppression by D-Trp ${ }^{6}$ luteinizing hormone-releasing hormone microcapsules as treatment of precocious puberty. J Clin Endocrinol Metab 65: 946-953.

11. Kappy M, Stuart T, Perelman A, Clemons R (1989) Suppression of gonadotropin secretion by a longacting gonadotropin-releasing hormone analog (leuprolide acetate, Lupron Depot) in children with precocious puberty. J Clin Endocrinol Metab 69: 1087-1089.

12. Wennink JMB, Waal HAD, Kessel H, Mulder GH, Foster JP, Schoemaker J (1988). Luteinizing hormone secretion patterns in boys at the onset of puberty measured using a highly sensitive immunoradiometric assay. J Clin Endocrinol Metab 67: 924-928.

13. Boyer RM, Finkelstein JW, Roffwarg HP, Kapen S, Weitzmen ED, Hellman L (1972) Synchronization of augmentated luteinizing hormone secretion with sleep during puberty. $N$ Engl J Med 287: 582-586.

14. Jakacki RI, Kelch RP, Sauder SE, LLoyd JS, Hopwood NJ, Marchall JC (1982) Pulsatile secretion of luteinizing hormone in children. J Clin Endocrinol Metab 55: 453-457.

15. Dickerman Z, Prager-Lewin R, Laron Z (1976) Response of plasma $\mathrm{LH}$ and FSH to synthetic LH-RH in children at various pubertal stages. $\mathrm{Am} \mathrm{J}$ Dis Child 130: 634-638.

16. Girard J, Baumann JB, Bühler U, Zuppinger K, Haas HG, Staub JJ, Wyss HI (1978) Cyproterone acetate and ACTH adrenal function. J Clin Endocrinol Metab 47: 581-6.

17. Savage DCL, Swift PGF (1981) Effect of cyproterone acetate on adrenal function in children with precocious puberty. Arch Dis Child 56: 218-222.

18. Sorgo WK, Kiraly E, Homoki J, Heinze E, Teller WM, Bierich JR, Moeller H, Ranke MB, Butenandt O, Knorr D (1987) The effects of cyproterone acetate on statural growth in children with precocious puberty. Acta Endocrinol (Copenh) 115: 44-49. 